\title{
Aneurysmal bone cysts of the spine
}

\author{
Mehmet Zileli $\cdot$ Hasan Serdar Isik $\cdot$ \\ Fatih Ersay Ogut $\cdot$ Merih Is $\cdot$ Sedat Cagli $\cdot$ \\ Cem Calli
}

Received: 6 January 2012/Revised: 2 August 2012 / Accepted: 9 September 2012/Published online: 1 October 2012

(C) The Author(s) 2012. This article is published with open access at Springerlink.com

\begin{abstract}
Purpose Aneurysmal bone cyst is a benign, relatively uncommon lesion, representing $1.4 \%$ of primary bone tumors. The vertebral column is involved in $3-30 \%$ of cases. This report describes clinical characteristics and treatment results of 18 patients with aneurysmal bone cyst of the spine.

Methods Between 1991 and 2008, 18 patients with aneurysmal bone cyst of the spine were surgically treated in our department. The clinical records, radiographs, histologic sections, and operative reports were analyzed.

Results There were 11 male and 7 female patients; mean age was 22.1 years (range 7-46 years). Localizations were cervical (3), cervicothoracic (2), thoracic (3), lumbar (4), and sacrum (6). Tumor was localized on the left side in 11 cases, on the right side in 2 and at midline in 5 patients. The two most common clinical features were axial pain
\end{abstract}

M. Zileli · S. Cagli

Department of Neurosurgery, Ege University, Izmir, Turkey

M. Zileli $(\bowtie)$

1421 sok 61/5, Alsancak, Izmir 35230, Turkey

e-mail: zilelim@gmail.com

H. S. Isik

Department of Neurosurgery, Ordu University, Ordu, Turkey

F. E. Ogut

Department of Neurosurgery, Gaziosmanpaşa University, Tokat, Turkey

M. Is

Depertment of Neurosurgery, Lutfi Kirdar Kartal Training and Research Hospital, Istanbul, Turkey

C. Calli

Department of Radiology, Ege University, Izmir, Turkey
(14 patients) and radicular pain (8 patients). Neurological signs were paraparesis in 3 , monoparesis in 6 . Mean duration of symptoms was 9 months (range 3 months3 years). All patients underwent surgery: total removal was performed in 13 patients and subtotal resection in 5. Posterior (11), anterolateral (1), or combined anterior-posterior (6) approaches were used. Mean follow-up duration was 112.3 months (range 4-21 years). We detected four recurrences in subtotal excision group (4/5), and one recurrence in total excision group (1/13).

Conclusion Treatment options for aneurysmal bone cysts are simple curettage with or without bone grafting, complete excision, embolization, radiation therapy, or a combination of these modalities. Radical surgical excision should be the goal of surgery to decrease the recurrence rate. Recurrence rate is significantly lower in case of total excision.

Keywords Aneurysmal bone cyst - Spine tumor . Spinal fusion - Tumor recurrence

\section{Introduction}

Aneurysmal bone cyst (ABC) is a benign, tumor-like, highly vascular, locally aggresive, and relatively rare osteolytic lesion of unknown etiology [1]. The lesions primarily occur in the first two decades of life, with slight women predominance [2, 3]. After osteoid osteoma and osteoblastoma, $\mathrm{ABC}$ is the third most frequent benign bone tumor. Primary ABCs represent $1.4 \%$ of primary bone tumors and the vertebral column, especially lumbar area and posterior elements are involved in 3-30\% of cases [4, 5]. Pain is the most common complaint, occurs especially at night, and it is localized to the site of the lesion. Direct radiographs, 
computed tomography (CT), and magnetic resonance imaging (MRI) help in diagnosis. Direct radiographs show an expansile osteolytic cavity. Fluid-fluid levels may be seen on both CT and MRI [6]. Management of ABCs of the spine is controversial. Options of treatments of ABCs in spine are surgical resection, radiation therapy, cryotherapy, and embolization [5, 7].

The purpose of this study is to describe the incidence, clinical presentation, diagnostic and therapeutic options, recurrence rate of the patients with $\mathrm{ABC}$ of the spine in our institute.

\section{Methods}

Eigtheen patients with ABCs in the spine were surgically treated in our department between 1995 and 2010. The clinical records, radiographs, histologic sections, and operative reports were analyzed. The mean follow-up duration was 112.3 months (ranged from 4 to 15 years).

\section{Results}

There were 11 male and 7 female patients; mean age was 22.1 years (range 7-46 years). Localizations were cervical (3), cervicothoracic (2), thoracic (3), lumbar (4), and sacrum (6). Tumor was localized on the left side in 11 cases, on the right side in 2 , and at midline in 5 . The two most common clinical features were axial pain (14 patients) and radicular pain (8 patients). Nine patients had no neurological symptoms, while six patients had motor weakness due to root compression, and three patients had motor weakness due to cord compression.

Mean duration of symptoms was 9 months (3 months3 years). Preoperative findings of patients were summarized in Table 1.

Direct radiology disclosed bone erosion in 15 cases. MRI was carried out in 17 patients; one patient underwent CT myelography for diagnosis. Among 17 patients diagnosed with MRI, bone edema was present in six cases. Vascularization was moderate in nine patients, prominent in six, and there were no signs of vascularization in two cases. Upon radiological examination with CT scan or MRI, canal compression was verified in 13 patients: 5 were mild, three were moderate, and 6 were severe. There was no canal compression in four patients. Paravertebral soft tissue mass was determined in 15 cases. There were fluidfluid levels in 10 cases (Table 2). According to Weinstein, Boriani, Biagini [8, 9] (WBB, Fig. 1) surgical staging, 17 cases were stage $\mathrm{ABCD}$ and one patient was stage $\mathrm{ABC}$.

All patients underwent surgery. Total removal could be performed in 13 patients. It was a spondylectomy in one patient. Subtotal resection was performed in five patients. Surgical approaches were posterior alone (11), posterior and lateral (1), and combined anterior-posterior (6) (Figs. 2, 3). Combined approaches were done in one session in five cases, and separate sessions in one case. One

Table 1 Pre-operative findings of patients

\begin{tabular}{lllllll}
\hline No. & Age, sex & Localization & Side & WBB stage & Symptom duration $(\mathrm{m})$ & Symptoms and findings \\
\hline 1 & $17, \mathrm{~F}$ & $\mathrm{C} 2$ & Left & $3-7$ ABCD & 3 & Neck pain, no neurology \\
2 & $15, \mathrm{~F}$ & $\mathrm{C} 6$ & Left & $1-7$ ABCD & 6 & Neck pain, left arm paresis \\
3 & $46, \mathrm{~F}$ & $\mathrm{C} 6-\mathrm{C} 7$ & Left & $1-8,12 \mathrm{ABCD}$ & 4 & Neck pain, left arm weakness \\
4 & $7, \mathrm{M}$ & $\mathrm{C} 7-\mathrm{T} 2$ & Left & $1-12 \mathrm{ABCD}$ & 3 & Back pain, paraplegia \\
5 & $8, \mathrm{M}$ & T1-T2 & Right & $1,2,5-12 \mathrm{ABCD}$ & 9 & Neck pain, radicular pain, no neurology \\
6 & $10, \mathrm{M}$ & T7-T8 & Midline & $1-3,10-12 \mathrm{ABCD}$ & 1 & Paraplegia \\
7 & $40, \mathrm{M}$ & T11 & Left & $8-11$ ABCD & 1 & Back pain, no neurology \\
8 & $18, \mathrm{M}$ & T12-L1 & Left & $1-3,12 \mathrm{ABCD}$ & 4 & Paraparesis \\
9 & $30, \mathrm{M}$ & L2 & Midline & $4-10 \mathrm{ABCD}$ & 24 & Low back and leg pain, no neurology \\
10 & $18, \mathrm{M}$ & L3 & Left & $3-7 \mathrm{ABCD}$ & 3 & Low back and left leg pain, monoparesis \\
11 & $17, \mathrm{M}$ & L4 & Left & $1-4,12 \mathrm{ABCD}$ & 5 & Left leg pain, no neurology \\
12 & $17, \mathrm{~F}$ & L5 & Midline & $1,2,11,12 \mathrm{ABC}$ & 36 & Low back pain, no neurology \\
13 & $15, \mathrm{M}$ & L5-sacrum & Right & $1-12 \mathrm{ABCD}$ & 3 & Low back and left leg pain, paraparesis \\
14 & $13, \mathrm{~F}$ & L5-sacrum & Left & $2-6 \mathrm{ABCD}$ & 12 & Low back and left leg pain, no neurology \\
15 & $22, \mathrm{~F}$ & L5-sacrum & Midline & $2-11, \mathrm{ABCD}$ & 12 & Low back pain, paraparesis \\
16 & $29, \mathrm{M}$ & Sacrum & Left & $2-8 \mathrm{ABCD}$ & 24 & Low back pain, no neurology \\
17 & $32, \mathrm{~F}$ & Sacrum & Left & $1-8,11,12 \mathrm{ABCD}$ & 12 & Left leg pain, left monoparesis \\
18 & $43, \mathrm{M}$ & Sacrum & Midline & $1-12 \mathrm{ABCD}$ & 1 & Low back and leg pain, no neurology
\end{tabular}

$M$ Male, $F$ Female 
Table 2 Radiological findings of patients

\begin{tabular}{|c|c|c|c|c|c|c|c|c|}
\hline No. & $\begin{array}{l}\text { Source of } \\
\text { radiology }\end{array}$ & Localization & $\begin{array}{l}\text { Plain } \\
\text { radiogra. }\end{array}$ & $\begin{array}{l}\text { Canal } \\
\text { compression }\end{array}$ & $\begin{array}{l}\text { Fluid-fluid } \\
\text { levels }\end{array}$ & $\begin{array}{l}\text { Bone edema } \\
\text { in MRI }\end{array}$ & $\begin{array}{l}\text { Para vertebral } \\
\text { mass }\end{array}$ & $\begin{array}{l}\text { Vascularization } \\
\text { in MRI }\end{array}$ \\
\hline 1 & X-ray, CT, MRI & $\mathrm{C} 2$ & Normal & + & Yes & No & Yes & ++ \\
\hline 2 & X-ray, CT, MRI & $\mathrm{C} 6$ & Erosion & - & Yes & Yes & Yes & +++ \\
\hline 3 & X-ray, CT, MRI & C6-C7 & Erosion & + & Yes & Yes & Yes & ++ \\
\hline 4 & X-ray, MRI & $\mathrm{C} 7-\mathrm{T} 2$ & Erosion & +++ & No & No & Yes & +++ \\
\hline 5 & X-ray, CT, MRI & $\mathrm{T} 1-\mathrm{T} 2$ & Erosion & - & Yes & No & Yes & ++ \\
\hline 6 & X-ray, MRI & $\mathrm{T} 7-\mathrm{T} 8$ & Erosion, fracture & +++ & No & Yes & Yes & +++ \\
\hline 7 & X-ray, CT, MRI & $\mathrm{T} 11$ & Normal & - & No & Yes & No & - \\
\hline 8 & X-ray, CT myelography & $\mathrm{T} 12-\mathrm{L} 1$ & Erosion & +++ & No & NA & Yes & NA \\
\hline 9 & X-ray, CT, MRI & L2 & Erosion & ++ & Yes & No & No & ++ \\
\hline 10 & X-ray, CT, MRI & L3 & Erosion & ++ & Yes & Yes & Yes & ++ \\
\hline 11 & X-ray, CT, MRI & L4 & Erosion & ++ & Yes & No & Yes & ++ \\
\hline 12 & X-Ray, CT, MRI & L5 & Normal & - & No & No & No & - \\
\hline 13 & X-ray, CT, MRI & L5-sacrum & Erosion & +++ & Yes & No & Yes & +++ \\
\hline 14 & X-ray, CT, MRI & L5-sacrum & Erosion & +++ & Yes & No & Yes & ++ \\
\hline 15 & X-ray, CT, MRI & L5-sacrum & Erosion & +++ & Yes & No & Yes & ++ \\
\hline 16 & X-ray, CT, MRI, DSA & Sacrum & Erosion & + & No & No & Yes & +++ \\
\hline 17 & X-ray, CT, MRI, DSA & Sacrum & Erosion & + & No & Yes & Yes & +++ \\
\hline 18 & X-ray, CT, MRI & Sacrum & Erosion & + & No & No & Yes & ++ \\
\hline
\end{tabular}

+ Mild, ++ Moderate, +++ Severe, $N A$ non available, $D S A$ digital subtraction angiography

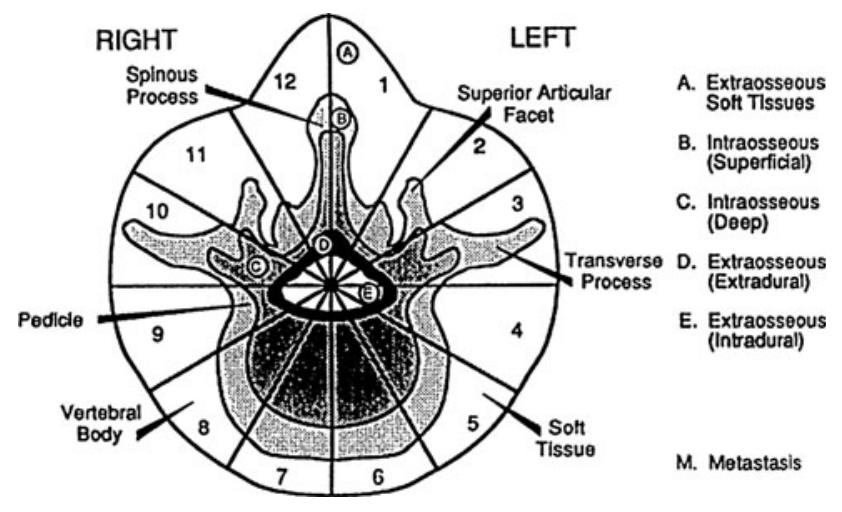

Fig. 1 WBB (Weinstein, Boriani, Biagnini) Surgical Staging System. The transverse extension of the vertebral tumor is described with reference to 12 radiating zones (numbered $1-12$ in a clockwise order) and to five concentric layers (A-E, from the paravertebral extraosseous compartments to the dural involvement). The longitudinal extent of the tumor is recorded according to the levels involved. From Boriani [9]

patient had a repeat surgery due to recurrence. Six patients were instrumented in addition to tumor removal. Tumor bed was supported with polymethyl methacryate (PMMA) in three patients and with autografts and cage in four patients. On last follow-up, 13 patients have no evidence of disease and five cases are alive with disease (Table 3). As complication, one patient had cerebrospinal fluid (CSF) collection at the site of incision and two patients had significant bleeding during surgery which needed blood transfusion.

\section{Discussion}

The prevalence of $\mathrm{ABCs}$ is 1.4 cases per 100,000 individuals, and they constitute approximately $1 \%$ of all bone tumors $[2,7]$. The lesions primarily occur in the first two decades of life, with slight women predominance [10]. In this study, mean age was 22.1 years similar with the literature but we have a male predominance $(61 \%)$.

$\mathrm{ABCs}$ are benign, highly vascular, locally aggressive tumors and recurrence rates after curettage were reported equal or less than $50 \%[1,3]$. Spontaneous regression of the tumor is uncommon [11]. Malghem [12] has reported spontaneous healing in three patients.

$\mathrm{ABCs}$ have a predilection for the lumbar spine in the series of Boriani and De Kleuver [7, 13]. In contrast, in Papagelopoulos' and Vergel de Dios' series, cervical and thoracic spine were involved more than lumbar spine $[3,5]$. In our series, sacrum and lumbar spine were involved more than others.

The combination of radiographs, CT scans, and MRI is diagnostic in many cases. Characteristic ballooning of the posterior elements with a thin rim may be shown on plain radiographs [14]. CT imaging reveals multiloculated lytic 

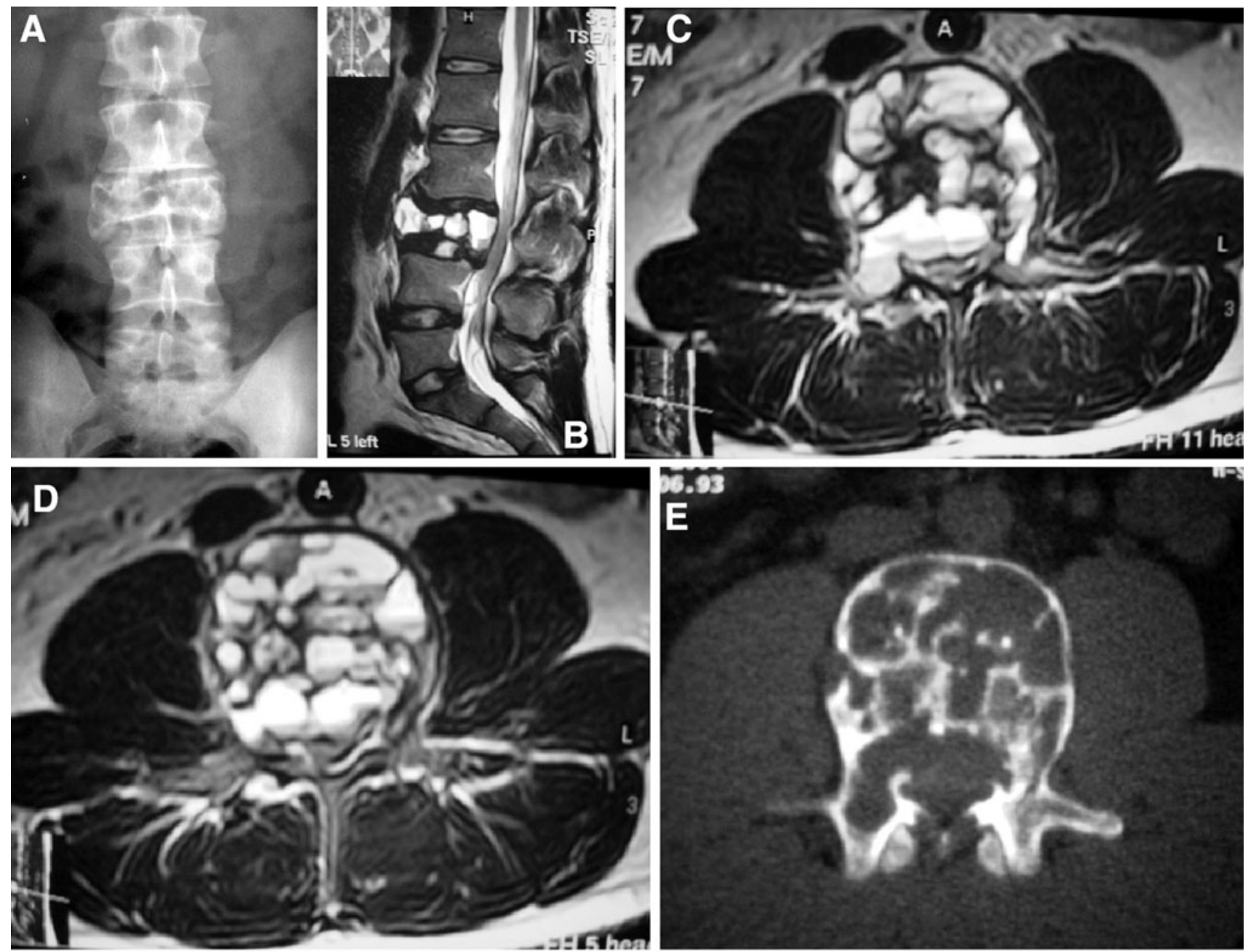

E

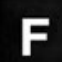

F

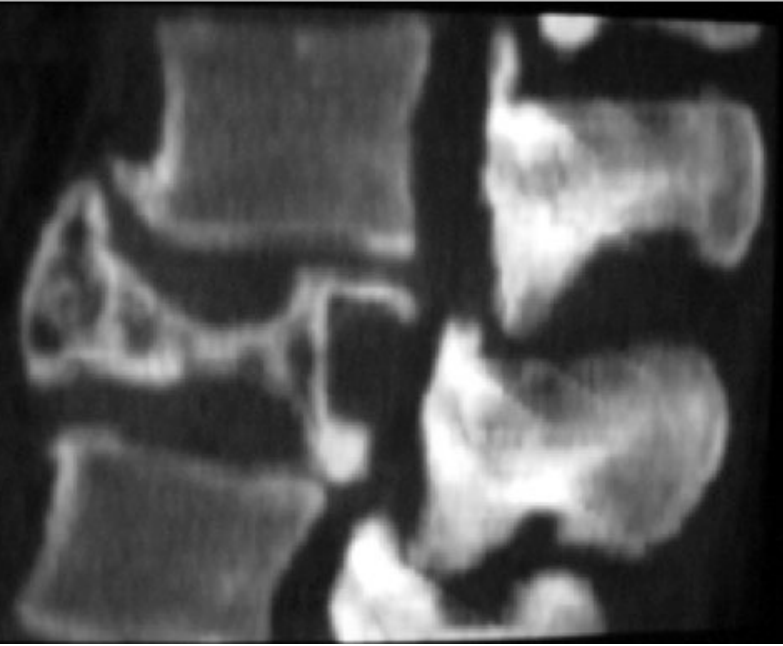

Fig. 2 a-l Case \# 7. A 30-year-old male was admitted to our department with low-back and leg pain for 2 years. There were no neurological deficits. MR and CT images revealed an L3 aneurysmal bone cyst with moderate canal compromise. There were fluidfluid levels, but no soft tissue mass. WBB scale was 4-10 ABCD.

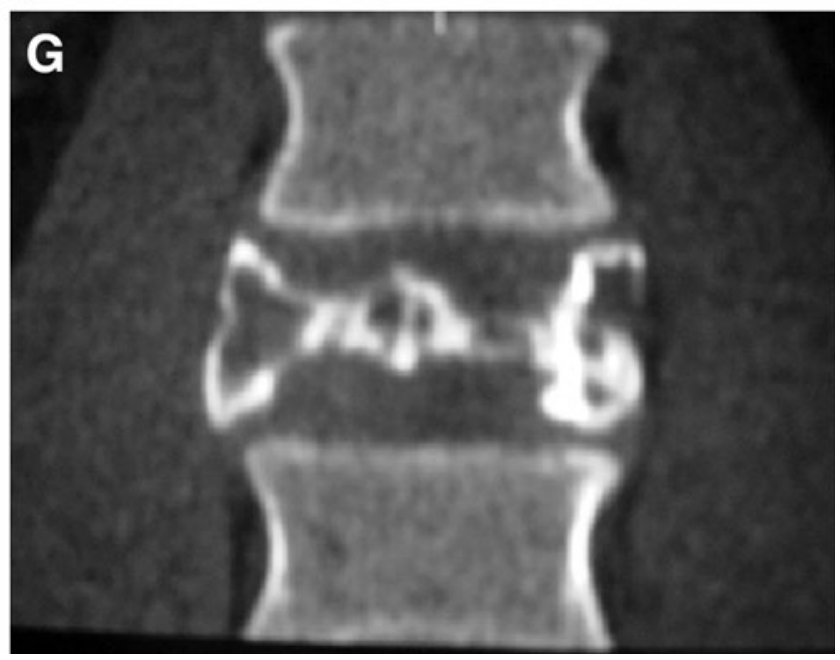

A combined surgical approach (first anterior, then posterior) with gross total removal was performed. A vertebral body cage and posterior pedicle fixation system were used to reconstruct and stabilize the spine. There was no recurrence during the 26-month follow-up time 

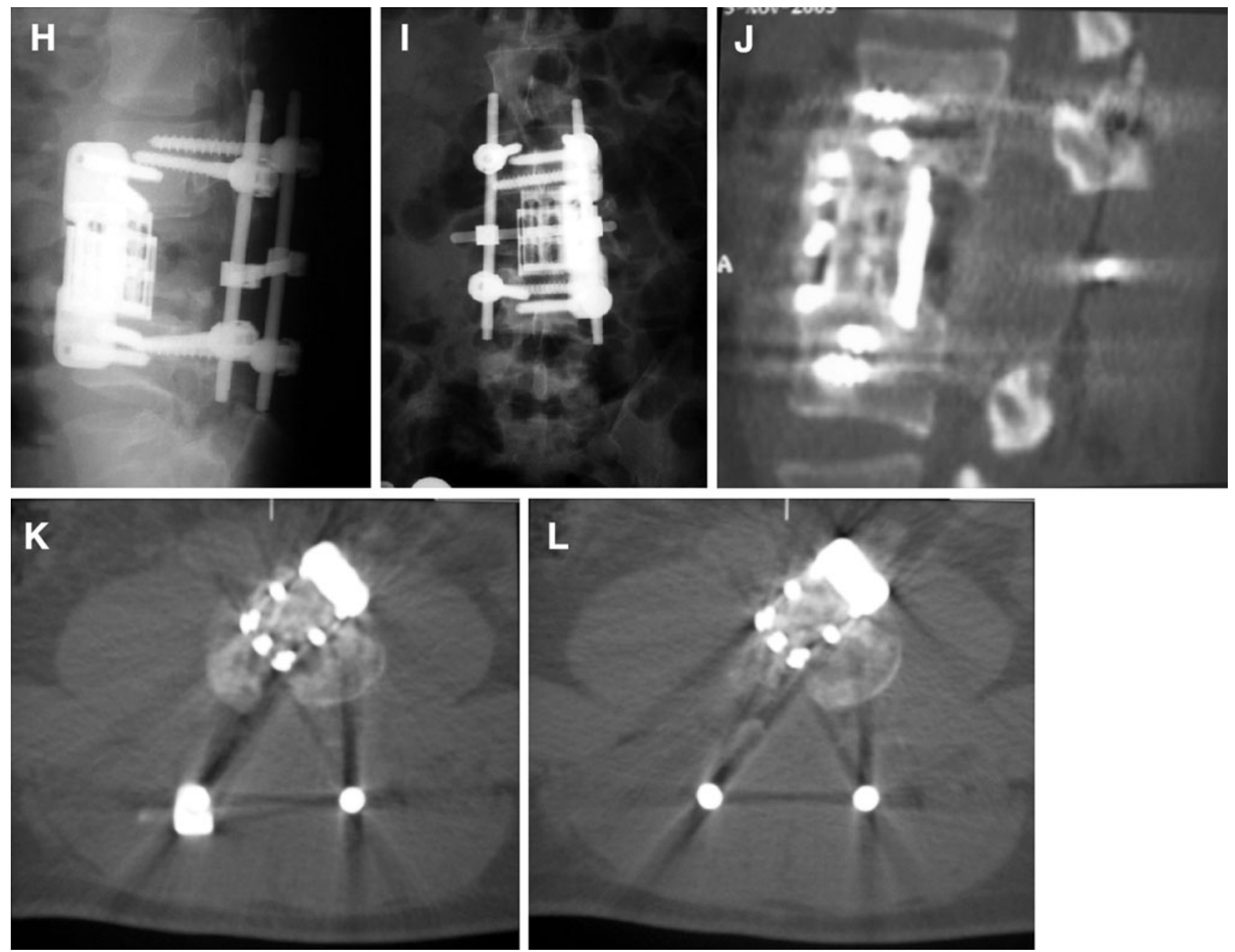

Fig. 2 continued

lesions with multiple internal septations, pathologic fracture or vertebral body collapse. CT scans are also useful for planning of possible instrumentation landmarks during surgery [15]. On MR imaging, ABCs usually demonstrate a thin, well defined rim of low signal intensity in the periphery and they are seen as multiseptate lesions. Usually each lobule represents different signal characteristics giving the tumor a heterogenous appearance. Both CT and MRI are important diagnostic tools for planning the surgical management [7]. We performed both CT and MR for the diagnosis.

Fluid-fluid levels can be seen in the $\mathrm{ABC}$, but this finding is not specific for ABCs. This appearance is also seen in the other bone lesions, which contain areas of hemorrhage or necrosis such as telangiectatic osteosarcoma, giant cell tumor, and chondroblastoma [16]. Differential diagnosis of ABCs includes giant cell tumor, chondroblastoma, chondromyxoid fibroma, fibrosarcoma, telangiectatic osteosarcoma, fibrous dysplasia, simple bone cyst, osteoblastoma, and plasmocytoma [4, 17]. Keenan et al. [18] reported that in their series of patients the incidence of fluid-fluid levels was $85 \%$. However, in our study fluidfluid levels were present only in 10 of 18 cases $(55 \%)$. This may be because we only evaluated spinal ABCs whereas Keenan et al. have included ABCs originating from the whole skeleton. The question whether spinal ABCs show less frequent fluid-fluid levels than the other parts of the skeleton should be answered through further imaging studies. Another point was to determine whether the nature of ABCs (having fluid-fluid levels versus solid) have influenced the results of the surgical treatment. However, there was no significant difference of the recurrence rates of cystic or solid type of aneurysmal bone cysts.

Although CT an MR are diagnostic methods for many cases, it is noted that in the literature, biopsy is necessary for confirmation, since many bone lesions can have a similar appearance [19]. However, it must be performed cautiously for sometimes needle biopsies can cause complications because the material obtained may consist of mostly blood elements. To prevent such complications, 

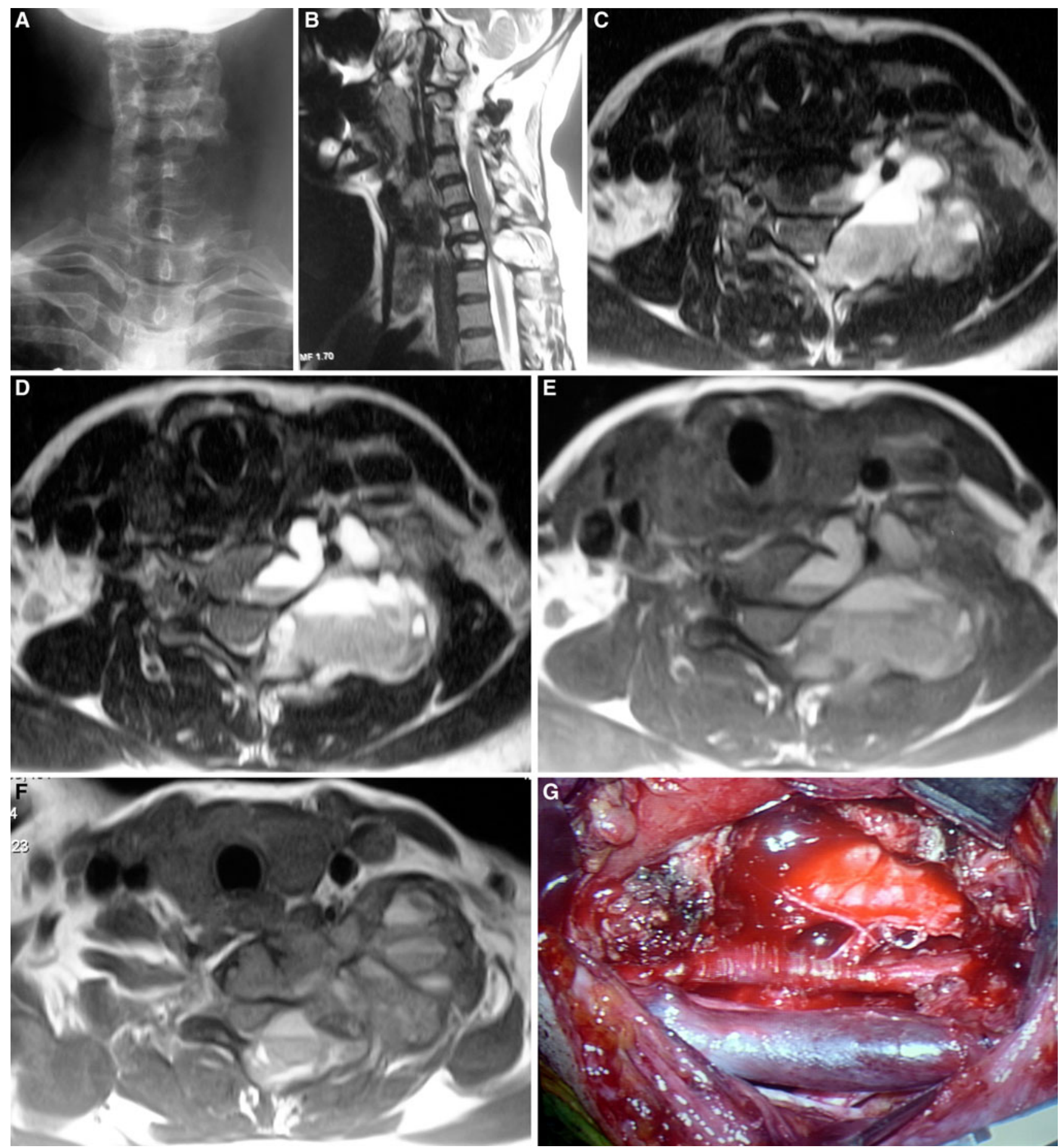

Fig. 3 a-m Case \# 2 A 46-year-old female came with neck pain, left arm weakness for 4 months. Neurological examination showed a monoparesis of left upper extremity. MR and CT scans showed a tumor on the left side of $\mathrm{C} 6$ and $\mathrm{C} 7$ vertebral bodies. C6, C7 body, C7 lamina, pedicle, facet joint, left $\mathrm{C} 6-\mathrm{C} 7$ neural foramina. WBB scale

open biopsy and frozen sections were recommended to establish the diagnosis [20]. In this study, biopsy was performed in six cases and we did not see any complication. was $1-8,12 \mathrm{ABCD}$. A total spondylectomy was performed using a combined posterior, anterior and posterior approach. Spinal reconstruction was achieved using a fibula allograft, anterior cervical plate and posterior lateral mass screw-rod system. There was no recurrence during the 16-month follow-up period

Histological examination is definitely necessary to confirm the differential diagnosis. The histology of $\mathrm{ABC}$ is typically characterized by cavernous channels surrounded by a spindle cell stroma with osteoclast like giant cells and 

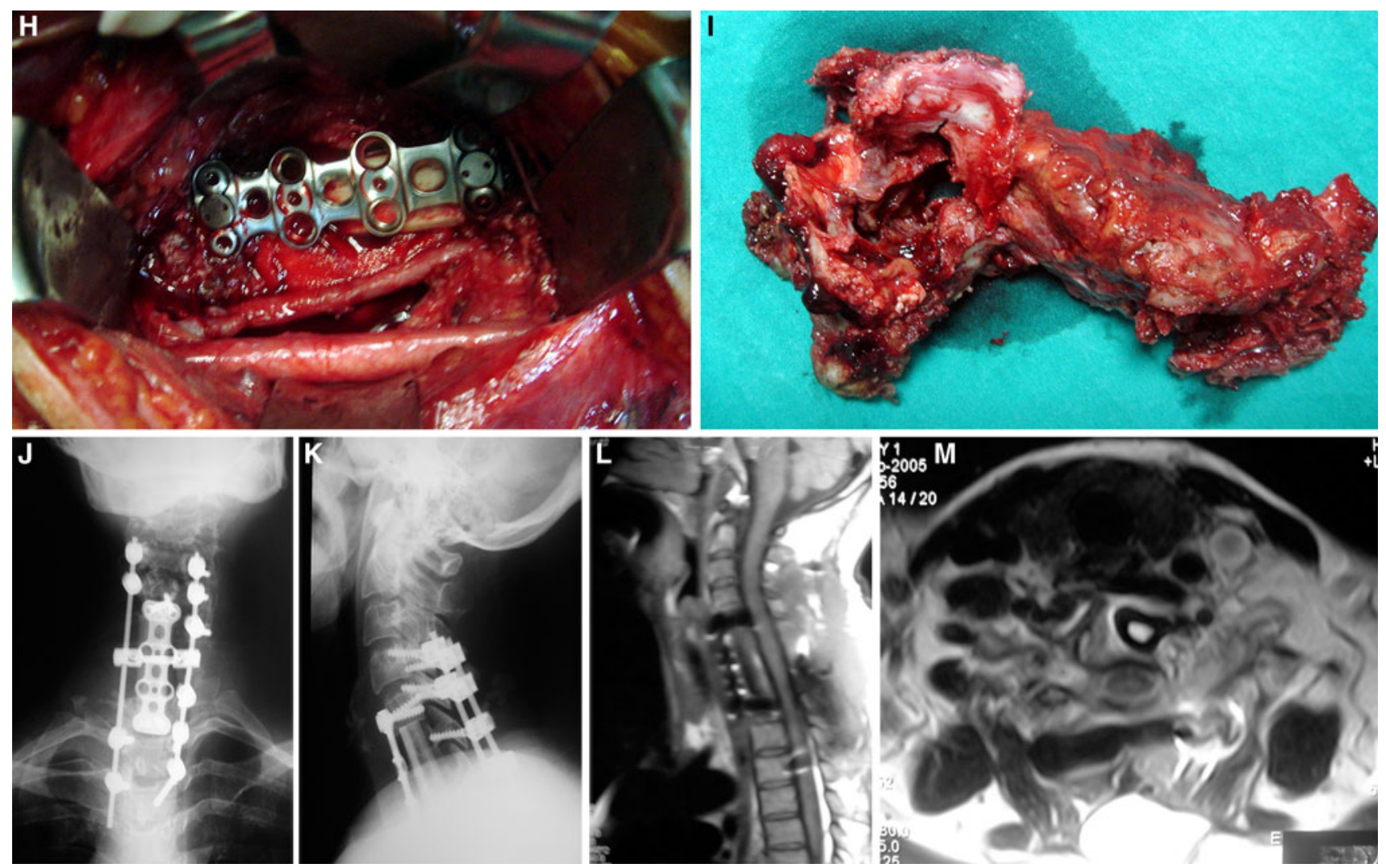

Fig. 3 continued

Table 3 Treatment of patients

\begin{tabular}{|c|c|c|c|c|c|c|c|c|}
\hline No. & Localization & $\begin{array}{l}\text { Surgery and } \\
\text { approach }\end{array}$ & $\begin{array}{l}\text { No. of } \\
\text { surgeries }\end{array}$ & $\begin{array}{l}\text { Tumor } \\
\text { removal }\end{array}$ & Implant, graft & Complication & $\begin{array}{l}\text { Follow-up } \\
\text { (months) }\end{array}$ & Last status \\
\hline 1 & $\mathrm{C} 2$ & Post and lat & 1 & Total & Post fixation, Ant cage and autograft & None & 66 & NED \\
\hline 2 & C6-C7 & Comb. post-ant & 1 & Total & $\begin{array}{c}\text { Anterior plate and autograft, } \\
\text { posterior screw and rod }\end{array}$ & None & 118 & NED \\
\hline 3 & C6 & Comb. ant-post & 1 & Subtotal & Posterior plate & CSF collection & 90 & AWD \\
\hline 4 & $\mathrm{C} 7-\mathrm{T} 2$ & Post then ant & 2 & Total & Anterior plate & None & 158 & NED \\
\hline 5 & $\mathrm{~T} 1-\mathrm{T} 2$ & Comb. post-ant & 1 & Total & Posterior and anterior plate & None & 79 & NED \\
\hline 6 & $\mathrm{~T} 7-\mathrm{T} 8$ & Post & 1 & Total & None & None & 202 & NED \\
\hline 7 & $\mathrm{~T} 11$ & Post & 1 & Total & None & None & 55 & NED \\
\hline 8 & T12-L1 & Post & 1 & Subtotal & None & None & 257 & AWD \\
\hline 9 & L2 & Comb. ant-post & 1 & Total & Cage, pedicle fixation & None & 99 & NED \\
\hline 10 & L3 & Post & 1 & Total & None & None & 136 & NED \\
\hline 11 & L4 & Post & 1 & Total & None & None & 77 & NED \\
\hline 12 & L5 & Post & 1 & Total & None & None & 155 & NED \\
\hline 13 & L5-sacrum & Post & 1 & Subtotal & PMMA & None & 115 & NED \\
\hline 14 & L5-Sacrum & Post & 1 & Total & PMMA & None & 57 & NED \\
\hline 15 & L5-Sacrum & Post & 1 & Subtotal & PMMA & Over bleeding & 45 & AWD \\
\hline 16 & Sacrum & Post & 1 & Subtotal & None & None & 147 & AWD \\
\hline 17 & Sacrum & Comb. post-ant & 1 & Total & None & Over bleeding & 83 & AWD \\
\hline 18 & Sacrum & Post & 1 & Total & None & None & 86 & NED \\
\hline
\end{tabular}

CSF cerebrospinal fluid, NED no evidence of disease, $A W D$ alive with disease, PMMA Polymethyl methacryate 
osteoid production [21]. There are some hypotheses in the literature that the tumor is the result of either hemorrhage into the tumor, or a vascular disturbance of the bone, or improper repair of a traumatic subperiosteal hemorrhages [22].

Treatment of $\mathrm{ABC}$ is also controversial. The options for treatment are curettage with or without bone grafting, complete excision, arterial embolization, intralesional drug injections (steroid and calcitonin), and radiation [6, 8]. Early diagnosis and appropriate surgical treatment of $\mathrm{ABCs}$ in the spine remain the key factors to successful management [23]. Total excision with or without instrumentation is the optimal approach for local control of tumor and it prevents recurrence [19]. We performed 13 total and 5 subtotal excision with 5 recurrences in this series.

PMMA injection (vertebroplasty or kyphoplasty) may be used to reinforce the bony defects after curettage [24]. Three patients in this study were also reinforced by PMMA injections after removal. There are also reports that the injections of calcitonin or methyl prednisolone inside the $\mathrm{ABC}$ cavities are safe procedures with no side effects [14]. Radiotherapy was recommended in inoperable cases, but it has numerous and severe complications including osteonecrosis, gonodal damage, myelopathy and induction of osteosarcoma [3, 6]. Also, preoperative embolization may be performed to minimize intraoperative blood loss [19, 25]. In 2010, Rossi et al. [26] reported their experiences and they considered selective arterial embolization is a less invasive, more feasible, effective and repeatable alternative method to standard surgical treatments. However, we did not use that method in any case in this series.

Recurrence is reported in 10-44\% of the cases, and usually rare when the tumor is excised completely [3]. Ninty percent of recurrences occur within 2 years. Thus, post-treatment follow-up should be at least 24 months $[1,3,7]$. In this series, 13 of 18 patients had a radical surgical removal. We detected four recurrences in subtotal excision group (4/5), and one recurrence in total excision group (1/13). Hay et al. [4] reported that there were no recurrences when total excision was performed, and a $25 \%$ recurrence rate after partial excision. Total excision of large tumors results in bony instability, and instrumentation is necessary to maintain structural integrity [27]. It is also reported that careful preoperative planning is important for management of post excision spinal instability [19]. In this series, six patients have undergone spinal stabilization to prevent spinal deformity and instability.

\section{Conclusions}

Early diagnosis and appropriate surgical treatment of aneurysmal bone cysts in the spine remain the key factors to successful management. Although an effective spinal decompression and stabilization can be achieved by partial or subtotal excisions, recurrence rate is significantly lower in case of total excision. Complete tumor removal would provide a cure for this agressive pathology in long term follow-ups.

\section{Conflict of interest None.}

Open Access This article is distributed under the terms of the Creative Commons Attribution License which permits any use, distribution, and reproduction in any medium, provided the original author(s) and the source are credited.

\section{References}

1. Ruiter DJ, Van Rijssel TG, Van Der Velde EA (1977) Aneurysmal bone cysts: a clinicopathological study of 105 cases. Cancer 39:2231-2239

2. Leithner A, Windhager R, Lang S, Haas O, Kainberger F, Kotz R (1999) Aneurysmal bone cyst. A population based epidemiologic study and literature review. Clin Orthop Relat Res 363:176-179

3. Vergel de Dios AM, Bond JR, Shives TC, McLeod RA, Unni KK (1992) Aneurysmal bone cyst. A clinicopathologic study of 238 cases. Cancer 69:2921-2931

4. Hay MC, Paterson D, Taylor TK (1978) Aneurysmal bone cysts of the spine. J Bone Joint Surg Br 60:406-411

5. Papagelopoulos PJ, Currier BL, Shaughnessy WJ et al (1998) Aneurysmal bone cyst of the spine. Management and outcome. Spine 23:621-628

6. Tsai JC, Dalinka MK, Fallon MD, Zlatkin MB, Kressel HY (1990) Fluid-fluid level: a nonspecific finding in tumors of bone and soft tissue. Radiology 175(3):779-782

7. Boriani S, De Iure F, Campanacci L et al (2001) Aneurysmal bone cyst of the mobile spine: report on 41 cases. Spine. 26:27-35

8. Weinstein JN (1991) Differential diagnosis and surgical treatment of primary benign and malignant neoplasm. In: Frymoyer JW (ed) The adult spine: principles and practice. Raven Press, New York, pp 830-850

9. Boriani S, Weinstein JN, Biagini R (1997) Spine update: primary bone tumors of the spine. Terminology and surgical staging. Spine 22:1036-1044

10. Pennekamp W, Peters S, Schinkel C, Kuhnen C, Nicolas V, Muhr G, Frangen TM (2008) Aneurysmal bone cyst of the cervical spine. Eur Radiol 18:2356-2360

11. Saglik Y, Kapicioglu MI, Guzel B (1993) Spontaneous regression of aneurysmal bone cyst. A case report. Arch Orthop Trauma Surg 112(4):203-204

12. Malghem J, Maldague B, Esselinckx, Noel H, De Nayer P, Vincent A (1989) Spontaneous healing of aneurysmal bone cysts: a report of three cases. J Bone Joint Surg Br 71B:645-650

13. De Kleuver M, Van der Heul RO, Veraart BEEMJ (1998) Aneurysmal bone cyst of the spine: 31 cases and the importance of the surgical approach. J Pediatr Orthop B 7:286-292

14. Tonomura ET, Ramos P, Hemais PM, Marchiori E, Gasparetto EL (2008) Aneurysmal bone cyst at C2. Imaging evaluation after intralesional injection of calcitonin and methylprednisolone. Arq Neuropsiquiatr 66(3-B):711-715

15. Chan MS, Wong YC, Yuen MK, Lam D (2002) Spinal aneurysmal bone cyst causing acute cord compression without vertebral collapse: CT and MRI findings. Pediatr Radiol 32:601-604

16. DiCaprio MR, Murphy MJ, Camp RL (2000) Aneurysmal bone cyst of the spine with familial incidence. Spine 25(12):1589-1592 
17. Sundaram M, McDonald DJ, Steigman CK, Bocchini T (1997) Metachronous multiple aneurysmal bone cysts. Skeletal Radiol 26(9):564-567

18. Keenan S, Bui-Mansfield LT (2006) Musculoskeletal lesions with fluid-fluid level: a pictorial essay. J Comput Assist Tomogr 30:517-524

19. Saccomanni R (2008) Aneurysmal bone cyst of spine: a review of literature. Arch Orthop Trauma Surg 128:1145-1147

20. Mankin HJ, Hornicek FJ, Ortiz-Cruz E, Villafuerte J, Gebhardt MC (2005) Aneurysmal bone cyst: a review of 150 patients. J Clin Oncol 23:6756-6762

21. Al-Shamy G, Relyea K, Adesina A, Whitehead WE, Curry DJ, Luerssen TG, Jea A (2011) Solid variant of aneurysmal bone cyst of the thoracic spine: a case report. J Med Case Rep 5(261): $1-6$

22. Munk PL, Helms CA, Holt RG, Johnston J, Steinbach L, Neumann C (1989) MR imaging of aneurysmal bone cysts. AJR Am J Roentgenol 153(1):99-101
23. Garg S, Mehta S, Dormans JP (2005) Modern surgical treatment of primary aneurysmal bone cyst of the spine in children and adolescents. J Pediatr Orthop 25(3):387-392

24. Ropper AE, Cahil KS, Hanna JW, McCarthy EF, Gökaslan ZL, Chi JH (2011) Primary vertebral tumors: a review of epidemiologic, histological and imaging findings, Part 1: benign tumors. Neurosurgery 69:1171-1180

25. Brastianos P, Gökaslan Z, McCarthy EF (2008) Aneurysmal bone cysts of the sacrum: a report of ten cases and review of the literature. Lowa Orthop J 29:74-78

26. Rossi G, Rimondi E, Bartalena T, Gerardi A, Alberghini M, Staals EL, Errani C, Bianchi G, Toscana A, Mercuri M, Vanel D (2010) Selective arterial embolization of 36 aneurysmal bone cysts of the skeleton with N-2-butyl cyanoacrylate. Skeletal Radiol 39:161-167

27. Harrop JS, Schmidt MH, Boriani S, Shaffrey CI (2009) Aggressive benign primary spine neoplasms. Osteoblastoma, aneurysmal bone cyst and giant cell tumor. Spine 34:S39-S47 